\title{
Evaluation of Stress in Concurrence with Level of Oral Hygiene among Dental Undergraduates in Malaysia
}

\author{
Rajeev Arunachalam ${ }^{1}$, Vini Rajeev ${ }^{2}$, Soh P Chin ${ }^{3}$, Stephanie H Chait Wei ${ }^{4}$, Taatcaaayini A/P Shanmugavelu ${ }^{5}$, Sarath B Kurra ${ }^{6}$
}

\begin{abstract}
Aim and objective: This study aimed to scrutinize sources and degree of stress in dental undergraduates in Asian Institute of Medicine, Science and Technology (AIMST) Dental Center during clinical years and correlating clinically with their oral hygiene.

Materials and methods: A cross-sectional study was conducted among a total of 216 students including the third-, fourth-, and fifth-year dental students, and a modified version of the dental environment stress (DES) questionnaire was used to investigate the possible sources of stress during the clinical years. The results were evaluated using the statistical package for social sciences (SPSS) version 16. Basic descriptive statistics and Chi-square test were used to analyze and correlate the variables. A significant level was set at $p<0.05$.

Results: Total mean rank stress in terms of the academic year for the third year was 78.56, 125.6 in fourth, and 117.65 in the fifth year and was statistically higher for year 4 students. There is no statistical difference in the stress experienced by male and female undergraduate students. In response to the questionnaire pertaining to the source of stressors, an overall four-point Likert scale scoring of stress was marked as mild to moderate by the majority of the students. Pertaining to the level of oral hygiene to stress, statistical significance was noted with year 5 with a mean value higher for year 3 students.

Conclusion: The overall findings of this investigation showed that dental students of AIMST University perceived comparatively mild-to-moderate levels of stress across the clinical study years.

Clinical significance: Assessment of potential sources of stressors in the dental curriculum will point out the areas that need to be focused so that effective management can be instituted.

Keywords: Dentistry, Oral hygiene, Stress, Undergraduates.

World Journal of Dentistry (2021): 10.5005/jp-journals-10015-1780
\end{abstract}

\section{INTRODUCTION}

The word "stress" was first used in life science by Hans Selye in 1936. 'Dental education can be a weighty source of stress among dental students, and literature highlights higher levels of stress among dental students than in the general population. ${ }^{2} \mathrm{~A}$ large body of research examining stress in undergraduate dental students has revealed a significant increase in stress that deepens with students' year of study.' Stress is a result of certain external physical or mental factors that affect an individual's physical and psychological well-being. ${ }^{3}$

Dental schools are known to be highly arduous and stressful learning environments as it is associated with a high level of stress in many aspects. ${ }^{4}$ Dental students have identified the development of stress due to many assignments, competition with other students, poor relationship with other students and teachers, anxious patients, fear of failure, complicated treatments and possible conflicts with patients, and limited time to perform and finish the planned treatment. ${ }^{5}$ Contemporary curricula require dental students to attain diverse proficiencies, including the acquisition of theoretical knowledge, clinical competencies, and interpersonal skills. ${ }^{6}$ This can cause stress during their practice as well as in their university life where they are supposed to enjoy the stress-free life as a university student. Studies have shown that oral changes that could appear as a consequence of stress include parafunctional habits like bruxism, myofascial pain dysfunction syndrome (MPDS), aphthous ulcers, oral lichen planus, xerostomia, and burning mouth syndrome. ${ }^{7-9}$ The possible mechanism by which psychological factors act on periodontium includes oral hygiene negligence leading to increase pocket depth, attachment loss, and tooth loss. ${ }^{10}$ \begin{tabular}{l} 
1Department of Periodontics, Faculty of Dentistry, Asian Institute of \\
Medicine, Science and Technology University, Kedah, Malaysia \\
${ }^{2}$ Department of Prosthodontics, Faculty of Dentistry, Asian Institute of \\
Medicine, Science and Technology University, Kedah, Malaysia \\
${ }^{3-5}$ Faculty of Dentistry, Asian Institute of Medicine, Science and \\
Technology University, Kedah, Malaysia \\
${ }^{6}$ Department of Pharmacology, Dhanalaksmi Srinivasan Medical \\
College and Hospital, Perambalur, Tamil Nadu, India \\
Corresponding Author: Vini Rajeev, Department of Prosthodontics, \\
Faculty of Dentistry, Asian Institute of Medicine, Science and \\
Technology University, Kedah, Malaysia, Phone: +60 16-4055204, \\
e-mail: rajeevarunachalam80@gmail.com \\
How to cite this article: Arunachalam R, Rajeev V, Chin SP, et al. \\
Evaluation of Stress in Concurrence with Level of Oral Hygiene among \\
Dental Undergraduates in Malaysia. World J Dent 2021;12(1):78-83. \\
Source of support: Nil \\
Conflict of interest: None \\
\hline \hline
\end{tabular}

Changes in dietary intake, habits such as smoking, bruxism can affect gingival circulation, alteration in salivary components and flow rate, hormonal changes, and lowered host resistance. During stress, the hypothalamic-pituitary-adrenal axis and the sympathetic nervous system interact and release glucocorticoids which have a myriad effect that disrupt homeostasis and lead to increased susceptibility to periodontal disease. ${ }^{11}$

Stress can be adverse emotion to unpleasant experiences and viewed as a process with both psychological and physiological components. Hence, the study aimed to analyze and the sources and degree of stress in the dental undergraduates in Asian Institute 
of Medicine, Science and Technology (AIMST) Dental Center during the clinical years and correlating the effect of stress on their oral hygiene by evaluating clinically. The objective of the study was to (1) identify the apparent sources of stress among AIMST dental undergraduates, (2) scrutinize specific stressors based on diverse clinical year of study and gender, (3) assess the pattern of stress among dental graduates in AIMST University assess the oral hygiene status among AIMST dental undergraduates, and (4) correlate the stress level and oral hygiene condition. The null hypothesis derived stated that the stress level will be more for the year 5 students as graduands, the level of stress could be moderate in AIMST University and that there is a correlation between stress and health of the oral environment.

\section{Materials and Methods}

A cross-sectional study was conducted in the Faculty of Dentistry, AIMST. A modified version of the dental environment stress (DES) questionnaire created was distributed among 216 students which included 75 students of year 3, 71 students of year 4, and 70 students of year 5 who were pursuing training for Bachelor of Dental Surgery at AIMST Dental center. Ethical clearance from the Institutional Ethics committee was obtained before the study. Informed consent of the participants was taken before the commencement of the study. The questionnaire included a total of 22 questions where the sources of stressor were further categorized under the following subheading which included: (a) influences by the operator themselves, (b) influences by the patient, and (c) influences by supervisors and staff on treatment procedures and protocols. All aspects pertaining to possible sources of stressors were addressed in the questionnaire. The questionnaire was responded based on a four-point Likert scale with response options of $1=$ not stressful, $2=$ slightly stressful, $3=$ moderately stressful, and $4=$ severely stressful, as well as a fifth possible response of not applicable. Based on the questionnaire, the total stress level and the average were calculated in terms of the academic year, gender, and various sources of a stressor for the participants. Clinical examination including the oral hygiene index by Greene and Vermilion, gingival index by Loe and Silness (wherever applicable) was assessed. For clinical evaluation, subjects were chosen by randomization which targeted 30 subjects each from the third, fourth, and fifth year of a dental undergraduate program with a total of 90 participants. The intention and rationale of the study were explained, and strict concealment was ensured. Gathered data using the self-administered questionnaire focusing on various sources of stressors during the clinical years and its clinical correlation were evaluated using the statistical package for social sciences (SPSS) version 16. Basic descriptive statistics and Chi-square test were used to analyze and correlate the variables. A significant level was set at $p<0.05$.

\section{Results}

The total number of 216 participants (100\%) which comprised 82 males (38\%) and 134 females (62\%) responded to the questionnaire. Among the participants, $34.7 \%$ were year 3 students, $32.9 \%$ were year 4 students, and $32.4 \%$ were year 5 students. Basic descriptive statistics and Chi-square test were used to analyze and correlate the variables at a significant level of $p<0.05$.

Based on the statistical analysis, the stress level of year 4 students was statistically significant and higher with a mean value of 125.6 compared to year 3 (78.56) and year 5 students (117.65) (Table 1). The study revealed that there is no statistical difference
Table 1: Comparison of stress level between various clinical years

\begin{tabular}{llc}
\hline Clinical year & Number & Mean rank \\
\hline Third year BDS & 71 & 78.56 \\
Fourth year BDS & 70 & $125.67^{*}$ \\
Fifth year BDS & 65 & 117.65 \\
\hline
\end{tabular}

${ }^{*} p<0.05$ significant compared fourth year BDS with other years

Table 2: Total stress level in term of the gender of students

\begin{tabular}{lccl}
\hline Gender & Number & Mean rank & Sum of ranks \\
\hline Male & 75 & 97.34 & $9,145.00$ \\
Female & 131 & 102.89 & $1,298.00$ \\
\hline
\end{tabular}

$p>0.05$ no significant difference in stress level between the genders

among gender in terms of stress in dental school (Table 2). The stressors were evaluated and were graded under three main categories (Table 3). The stress-related influence of the working environment was assessed with 13 related questions. The majority of the year 3 students marked mild to moderate in the Likert's scale for the stressors associated with the first category. The lack of confidence to be a successful dentist was one of the stressors which many of the year 3 students graded from moderate to high. Year 4 and year 5 students graded moderate for the majority of the stressors in this category. Competency and clinical quota completion were the main stressors that were graded high in this category by both year 4 and year 5 students. The second main category evaluated was the influence of the patient in inducing stress. The majority of the grading was dispersed from mild to high among year 3 students and among year 4 and year 5 majority marked mild to moderate. The third category of stressor analyzed was the influence of supervisors and staff on the stress level. The majority of year 3 and year 4 students graded from mild to high, whereas many of the year 5 students expressed the grading from mild to moderate. On statistical analysis, comparing the stressors among each year using the Chi-square test (Table 4), year 3 showed a statistical significance with a mean rank value of (98.90) related to the influence of working environment with other years, whereas year 4 (126.56) and year 5 did not have any significant difference (112.45). Year 3 mean rank (104.89) exhibited a statistical significance related to the influence of patients with other years, whereas year 4 mean rank (135.23) and year 5 did not have any significant difference (121.89). Based on the statistics, the influence of supervisors and staff was statistically insignificant for year 4 mean rank value (121.78) and year 5 (119.56) students, whereas year 3 (93.12) showed a significant difference compared to other years. Comparison of stress and associated changes in the oral environment was also statistically evaluated (Table 5). The mean \pm SD gingival index value of year $3(0.45 \pm 0.56)$ and year 4 students $(0.39 \pm 0.89)$ were statistically insignificant, whereas there was a considerable statistical difference with year $5(0.29 \pm 0.45)$ students. The oral hygiene index of year 3 the mean \pm SD $(0.84 \pm 0.45)$ and year 4 students $(0.75 \pm 0.23)$ were statistically insignificant and showed statistical significance with year $5(0.59 \pm 0.56)$ students. Based on the study, it was inferred that the students in all the clinical years exhibited the same amount of stress even though year 4 showed a higher mean value. The research among the dental undergraduates showed that the overall stress level is mild to moderate in AIMST University. The study also concluded that among the dental students, the oral environment is not affected by changes in stress level pattern. 
Table 3: Distribution of stress among the AIMST dental students

\begin{tabular}{|c|c|c|c|c|c|c|c|c|c|c|c|c|c|c|c|c|c|}
\hline \multirow[b]{2}{*}{ S. no. } & \multirow{2}{*}{$\begin{array}{l}\text { Source of } \\
\text { stressors }\end{array}$} & \multirow[b]{2}{*}{ Individual stressors } & \multicolumn{5}{|c|}{ Year 3} & \multicolumn{5}{|c|}{ Year 4} & \multicolumn{5}{|c|}{ Year 5} \\
\hline & & & 1 & 2 & 3 & 4 & 5 & 1 & 2 & 3 & 4 & 5 & 1 & 2 & 3 & 4 & 5 \\
\hline 1 & $\begin{array}{l}\text { Influence of } \\
\text { working en- } \\
\text { vironment }\end{array}$ & Amount of assigned work & 8 & 25 & 32 & 6 & & 2 & 18 & 40 & 10 & & 5 & 22 & 32 & 5 & \\
\hline 2 & & Full loaded day & 3 & 16 & 34 & 14 & 4 & 4 & 16 & 39 & 11 & & 2 & 17 & 41 & 5 & \\
\hline 3 & & $\begin{array}{l}\text { Fear of being unable to keep } \\
\text { up with the workload }\end{array}$ & 2 & 13 & 42 & 14 & & 4 & 18 & 33 & 15 & & 5 & 13 & 40 & 7 & \\
\hline 4 & & $\begin{array}{l}\text { Difficulty in learning preci- } \\
\text { sion manual skills required } \\
\text { in clinical and laboratory } \\
\text { work }\end{array}$ & 3 & 19 & 37 & 12 & & 1 & 17 & 40 & 12 & & 3 & 20 & 34 & 8 & \\
\hline 5 & & $\begin{array}{l}\text { Difficulty in learning clinical } \\
\text { procedures }\end{array}$ & 7 & 20 & 28 & 16 & & 3 & 20 & 32 & 15 & & 9 & 14 & 33 & 9 & \\
\hline 6 & & $\begin{array}{l}\text { Competition with class- } \\
\text { mates }\end{array}$ & 20 & 22 & 22 & 3 & 4 & 5 & 20 & 30 & 16 & 2 & 17 & 25 & 16 & 7 & \\
\hline 7 & & $\begin{array}{l}\text { Competency examinations } \\
\text { and grades }\end{array}$ & 3 & 8 & 37 & 23 & & 2 & 16 & 34 & 18 & & 2 & 9 & 31 & 23 & \\
\hline 8 & & $\begin{array}{l}\text { Completion of clinical } \\
\text { requirements (quota) }\end{array}$ & 8 & 25 & 28 & 2 & 8 & 8 & 4 & 39 & 19 & & 7 & 2 & 32 & 24 & \\
\hline 9 & & $\begin{array}{l}\text { Lack of confidence to be a } \\
\text { successful dentist }\end{array}$ & 5 & 22 & 30 & 13 & 1 & 6 & 7 & 44 & 13 & & 6 & 21 & 27 & 11 & \\
\hline 10 & & Lack of time for relaxation & 9 & 28 & 29 & 5 & & 11 & 16 & 31 & 12 & & 13 & 27 & 17 & 8 & \\
\hline 11 & & $\begin{array}{l}\text { Rules and regulations of the } \\
\text { faculty }\end{array}$ & 15 & 26 & 24 & 5 & & 14 & 24 & 25 & 7 & & 12 & 21 & 26 & 6 & \\
\hline 12 & & $\begin{array}{l}\text { Lack of home atmosphere in } \\
\text { living quarters/hostel }\end{array}$ & 16 & 21 & 24 & 10 & & 12 & 16 & 33 & 9 & & 14 & 19 & 65 & 7 & \\
\hline 13 & & $\begin{array}{l}\text { Lack of confidence in career } \\
\text { decision }\end{array}$ & 12 & 25 & 29 & 5 & & 12 & 22 & 28 & 8 & & 11 & 21 & 26 & 7 & \\
\hline 14 & $\begin{array}{l}\text { Influence by } \\
\text { patient }\end{array}$ & $\begin{array}{l}\text { Lack of patient for particular } \\
\text { cases }\end{array}$ & 6 & 12 & 22 & 15 & 16 & 5 & 21 & 28 & 13 & & 4 & 15 & 38 & 11 & \\
\hline 15 & & $\begin{array}{l}\text { Patients being late or not } \\
\text { showing for their appoint- } \\
\text { ments }\end{array}$ & 7 & 11 & 21 & 14 & 18 & 6 & 10 & 34 & 11 & 9 & 5 & 19 & 34 & 9 & 4 \\
\hline 16 & & $\begin{array}{l}\text { Patients not available at pre- } \\
\text { scribed times for treatment } \\
\text { or examination }\end{array}$ & 5 & 10 & 27 & 19 & 10 & 4 & 23 & 31 & 8 & 4 & 15 & 15 & 25 & 10 & \\
\hline 17 & & $\begin{array}{l}\text { Lack of cooperation by pa- } \\
\text { tients in their home care }\end{array}$ & 6 & 13 & 26 & 15 & 11 & 4 & 10 & 39 & 7 & 10 & 4 & 22 & 26 & 13 & \\
\hline 18 & & $\begin{array}{l}\text { Responsibilities for compre- } \\
\text { hensive patient care }\end{array}$ & 4 & 12 & 22 & 16 & 17 & 2 & 23 & 26 & 9 & 10 & 11 & 15 & 27 & 12 & \\
\hline 19 & $\begin{array}{l}\text { Influence by } \\
\text { supervisors } \\
\text { and staff }\end{array}$ & $\begin{array}{l}\text { Atmosphere created by } \\
\text { clinical supervisors }\end{array}$ & 3 & 12 & 32 & 17 & 7 & 4 & 17 & 33 & 16 & & 2 & 18 & 33 & 12 & \\
\hline 20 & & $\begin{array}{l}\text { Receiving criticism from } \\
\text { staff for academic or clinical } \\
\text { work }\end{array}$ & 8 & 19 & 29 & 13 & 2 & 9 & 19 & 27 & 15 & & 6 & 18 & 30 & 11 & \\
\hline 21 & & $\begin{array}{l}\text { Inconsistency of feedback } \\
\text { on your work among differ- } \\
\text { ent instructors }\end{array}$ & 4 & 17 & 29 & 16 & 5 & 15 & 21 & 28 & 6 & & 10 & 19 & 26 & 10 & \\
\hline
\end{tabular}

Four point Likert's scale $1=$ not stressful, $2=$ slightly stressful, $3=$ moderately stressful, and $4=$ severely stressful, $5=$ not applicable

\section{Discussion}

The present study was conducted among dental undergraduates in AIMST from the year 3 to year 5 to investigate sources and level of stress in dental undergraduates in AIMST during clinical years and correlating it with their oral hygiene. A modified version of the DES questionnaire based on the AIMST Dental center curriculum was used in the study to investigate the possible sources of stress in AIMST dental undergraduates. ${ }^{12}$ The survey consisted of 22 questions relating to possible sources of stress. The null hypothesis derived stated that the stress level will be more for the year 5 students as graduands, the stress level at AIMST University is moderate and that there is a significant correlation between 
Table 4: Total stress level in term of influences by the influence of the working environment, the influence of patients, and influence of supervisors and staff

\begin{tabular}{|c|c|c|c|c|}
\hline Year & Number & $\begin{array}{l}\text { Influence } \\
\text { of working } \\
\text { environment } \\
\text { mean rank }\end{array}$ & $\begin{array}{l}\text { Influence } \\
\text { of patients } \\
\text { mean rank }\end{array}$ & $\begin{array}{l}\text { Influence of } \\
\text { supervisors } \\
\text { and staff } \\
\text { mean rank }\end{array}$ \\
\hline $\begin{array}{l}\text { Third year } \\
\text { BDS }\end{array}$ & 71 & 98.90 & 104.89 & 93.12 \\
\hline $\begin{array}{l}\text { Fourth year } \\
\text { BDS }\end{array}$ & 70 & $126.56^{*}$ & $135.23^{*}$ & $121.78^{*}$ \\
\hline Fifth year BDS & 65 & $112.45^{*}$ & $121.89 *$ & $119.56^{*}$ \\
\hline
\end{tabular}

${ }^{*} p<0.05$ significant compared third BDS with others

Table 5: Comparison of clinical correlation of stress with gingival and oral hygiene index

\begin{tabular}{llll}
\hline Year & Number & $\begin{array}{l}\text { Gingival Index } \\
\text { (mean } \pm \text { SD) }\end{array}$ & $\begin{array}{l}\text { Oral hygiene index } \\
\text { (mean } \pm \text { SD) }\end{array}$ \\
\hline Third year BDS & 71 & $0.45 \pm 0.56^{*}$ & $0.84 \pm 0.45^{*}$ \\
Fourth year BDS & 70 & $0.39 \pm 0.89^{*}$ & $0.75 \pm 0.23^{*}$ \\
Fifth year BDS & 65 & $0.29 \pm 0.45$ & $0.59 \pm 0.56$ \\
\hline
\end{tabular}

${ }^{*} p<0.05$ significant compared fifth BDS with others

stress and health of the oral environment. Based on the study, year 4 students exhibited more amount of stress, thereby rejecting the hypothesis. All the questions detailed that the stress level varied between mild to moderate among the dental undergraduates in AIMST University and hence the null hypothesis was accepted. The third hypothesis was rejected based on the study as the result stated that there is no correlation between oral health and stress.

The majority of students from all the years found that the stress level is mild to moderate in AIMST University. The probable reason for the reduced stress level in AIMST University might be due to the importance given in various co-curricular activities along with academics to keep the young minds to be healthy and active. The students are also well trained to handle the workload with appropriate time management. The approachability of lecturers and the mentor-mentee program that maintains confidentiality as well as the freedom to share the experience and problems also enhances the confidence level in the majority of the students making it a suitable environment for academics.

Based on the study, the third-year dental students had the least stress level when compared to the other clinical years. The curriculum is module-based in the University and the year 3 students enter into patient-related clinical works only in module 3 and 4 where they will be demonstrated the basic procedures by the lecturers. This clearly states that it is the beginning of the clinical years, whereby students were expected to perform only the basic procedures with minimal complexity when compared to other clinical years. Besides that, it can be expected that year 3 students who were exposed to a new clinical environment does not deal with difficult and complex clinical cases and their clinical quota to be fulfilled is comparatively mild. Moreover, they can concentrate further on the other subjects thus alleviating the anxiety related to studies.

In this study, the total stress level in year 4 dental students was the highest and statistically significant to year 3 and year 5 students. This could be because these students are in a transition phase of adjusting from simple clinical procedures to a more complex hectic environment which is in agreement with the study conducted by Zeyad et al. ${ }^{13}$ Hence, the students take added time in adapting themselves to the setting. It can portray a sudden upsurge in the workload and complexity of the clinical cases as compared to those they have executed during their academic year 3. Above the clinical works, the year 4 students have to find a balance in dealing with the other subjects taught and might be the reason for the increased stress compared to other years.

The fifth-year dental students exhibited moderate stress levels among other years because they would have adapted to their work environment in terms of workload, clinical procedures, competency examinations, complexity, and difficulty of clinical cases. However, a certain stress level was still present which was caused by the need for quota completion before graduation and fear of passing the examination. Compared to year 5 , the total stress levels were more for year 4 because of change in work pattern, possibly due to concern of executing complex clinical procedures which necessitates more time to adjust. These outcomes concur with previous studies conducted by Al-Sowygh which also revealed that undergraduates in the changeover year from preclinical to clinical preparation had the highest stress. ${ }^{14}$ From the result, it shows that the dental students from all three academic years share an almost similar pattern of stress level throughout their studies and clinical practices. The mild to moderate level of stress exhibited might be due to the individual variation among students to complete their tasks, assignments, and responsibility in the respective year.

The present study showed that there was no statistical significance in stress with respect to gender. Studies conducted by Pau et al. stated that female dental students have higher stress levels than male dental students. ${ }^{15}$ In term of gender where we look at the sociological aspect, study conducted by Zeyad et al. have shown that females generally can handle stress better than males, thus the gender also plays an important roles in studying the stress level among dental undergraduates. ${ }^{13}$ The current study showed a similar result complying with other studies showing a very minimal increase in the mean value for female subjects. The influence of sociodemographic aspects on stress, such as age and cultural setting might be the reason for the mild increase in mean value of the result related to stress for females even though it was statistically not significant. ${ }^{16}$ The research by Saddki et al. in is in contradiction with the current study and states that undergraduate dental students show a low emotional intelligence (EI), female sex are affected more due to stress and being in the clinical years increases the perceived stress. ${ }^{17}$

The influence of working environment was statistically significant for year 3 students with the least stress compared to others but was insignificant between year 4 and year 5. "Clinical requirements" was one of the highest stressors among the fourthand fifth-year undergraduate students. This can be because completing clinical obligations is an essential part of every clinical course that should be achieved for the student to go on to the subsequent level. A study conducted by Rosli et al. stated that the prerequisite system of dental procedures met the peak stress scores for fifth-year students, which is in agreement with the current study.$^{18}$ Competency examination and grades were also considered as a high stressor among the dental graduates with more concerns by year 3 and year 5 students. All other factors related to the influence of working environment was graded mild to a moderate level by the students concluding that they were able to handle the workload well without affecting their personal life. 
The total stress level in terms of influences by patients included lack of patient for particular cases, patients being late or not showing for their appointments, patients not available at prescribed times for treatment or competency examinations. The task of getting appropriate patients and difficulty in managing patients related to home care and responsibilities related to comprehensive care induced moderate to severe stress among the students. Familiarity toward the patient, prior preparation for executing treatment procedures, and strict adherence to infection control measures, and motivating the patient on home care can help in alleviating the stress related to the patient.

In this study, the total stress level in term of influences by supervisors and staff where graded at mild to moderate by the majority of students in the Likert's scale and stressors assessed were the atmosphere created by clinical supervisors, receiving criticism from staff for academic or clinical work and inconsistency of feedback on your work among different instructors. On statistical analysis, year 4 dental students and year 5 students had comparatively higher stress levels compared to year 3 students. Year 4 had the highest mean value for stress level, fifth-year dental students had a moderate mean value for stress, and year 3 students had a less mean value for stress. It may be because the fifth-year dental students know how to communicate and discuss the problems faced with the supervisors and staff. Besides that, since they were the students who have already been in the faculty for the past 5 years, they will be more familiar with all the lecturers and staff, thus they do not have much difficulty in dealing and discussing with them. Third-year dental students who have just started their clinical practice do not have many chances to meet with the clinical staff, especially the technicians who usually deal with the prosthesis. Thus, the third-year students have much lower stress levels as compared to those in the fourth and fifth year.

Research by Peruzzo et al. showcases that stress and depressions are associated with periodontal destruction through behavioral and physiological mechanisms. ${ }^{19}$ Studies conducted by Goyal et.al. and Shiralkar et al. showed a progressive association between stress and periodontal conditions. ${ }^{20,21}$ In addition, oral care negligence during cycles of stress and depression was linked with periodontal attachment loss and missing teeth leading to increased periodontal breakdown. ${ }^{19}$ However, no statistical difference between stress and gum problems was observed in the present study, and participant's age could be the reason for the association that was observed. The results of this study showed that oral hygiene has a relationship with poor self-perceived oral health status rather than the level of stress that may induce oral conditions.

In this study, the gingival index and OHI-S score of third-year dental undergraduates were highest which may predispose to induce changes in the healthy periodontium. However, in this study, there is no highly significant relationship between the stress level and the periodontal conditions in dental undergraduates as it could be seen that year 3 students had the least amount of stress but the oral hygiene index was significantly lower for the same group. Year 4 and year 5 did not show any correlation to stress and oral hygiene. This could be attributed to the fact that the dental students who are exclusively involved in patient-related treatments are aware of the importance of good oral hygiene and its management that includes proper brushing techniques and use of the accessory aids like flossing, interdental brushes, and mouthwash.

The number of studies discussing the content and effectiveness of stress management programs for dental students is limited compared with studies discussing the sources of stress among dental students. $2,4,12-14,22$ The stress management programs reported in the literature for medical students were also limited and encompassed self-hypnosis, meditation, mindfulness-based stress reduction, changes in the "pass/fail" grading system, feedback on various health habits, educational discussion, and changes in the length and type of curriculum provided. ${ }^{21}$ This proved that stress is inescapable in dental students and can only be minimized by awarding a favorable environment to become an achiever.

Limitations of this research might be the selection of a small number of groups selected from a single university. Hence, to find a correlation between stress and oral conditions, a larger group of students from other universities, as well as respondents other than dental undergraduates, should be evaluated.

\section{Conclusion}

Stress has become the most conjoint singularity affecting the health of the population. Undoubtedly, this might also be reflected as the same notion in the field of dentistry. Most dental students will face some stress throughout their learning process no matter in the earlier year or the final year. Every student has their sources of stressor, thus the most important is to identify the source of the stressor and start to rule out the ways to manage them. It is essential to recognize factors that can modify stress so that appropriate interventions can be developed and implemented. However, the necessity for an educational intervention on recognizing and lowering stress should be instituted at an earlier time in the curriculum and will be beneficial to cope up with the stress.

\section{References}

1. Shilpa W, Prashant W, Kaustubh ST, et al. Stress and periodontal disease: a review. Int J Oral Res 2017;5(3):1-5.

2. Samar AS, Ebtissam MA, Nadia SA, et al. Survey of perceived stressinducing problems among dental students, Saudi Arabia. Saudi Dent J 2010;22(2):83. DOI: 10.1016/j.sdentj.2010.02.007.

3. Vettore MV, Leão AT, Monteiro Da Silva AM, et al. The relationship of stress and anxiety with chronic periodontitis. J Clin Periodontol 2003;30(5):394-402. DOI: 10.1034/j.1600-051X.2003.10271.x.

4. Acharya S. Factors affecting stress among Indian dental students. J Dent Educ 2003;67(10):1140-1148. DOI: 10.1002/j.00220337.2003.67.10.tb03707.x.

5. Mannem S, Chava VK. The effect of stress on periodontitis: a clinicobiochemical study. J Indian Soc Periodontol 2012;16(3):365369. DOI: 10.4103/0972-124X.100912.

6. Cayci E, Guzeldemir-Akcakanat E. The relationship between psychosocial factors and periodontal disease. Dentistry 2014;4:4.

7. Travell J. Temporomandibular joint pain referred from muscles of head and neck. J Prosthet Dent 1960;10(4):745. DOI: 10.1016/00223913(60)90257-2.

8. Neville BW, Damm DD, Allen CM, et al. Relation of stress and anxiety to oral lichen planus. Oral Surg Oral Med Oral Pathol 1986;61(1):44. DOI: 10.1016/0030-4220(86)90201-X.

9. Preeti L, Magesh K, Rajkumar K, et al. Recurrent aphthous stomatitis. J Oral Maxillofac Pathol 2011;15(3):252-256. DOI: 10.4103/0973029X.86669.

10. Rosania AE, Low KG, McCormick CM, et al. Stress, depression, cortisol, and periodontal disease. J Periodontol 2009;80(2):260-266. DOI: 10.1902/jop.2009.080334.

11. NoorAziella MN, Ahmad Zamir CD, Tengku Intan BTJ, et al. Perceived depression, anxiety and stress among UiTM dental undergraduates in clinical years. Environ Behavi Proceed J 2017;2(6):81. DOI: 10.21834/ebpj.v2i6.954. 
12. Garbee WH, Zucker SB, Selby GR. Perceived sources of stress among dental students. J Am Dent Assoc 1980;100(6):853-857. DOI: 10.14219/ jada.archive.1980.0279.

13. Zeyad HAS, Abdulmohsen AA, Mohammed IA, et al. Perceived causes of stress among Saudi dental students. King Saud University J Dent Sci 2013;4:7-15.

14. Al-Sowygh ZH. Academic distress, perceived stress and coping strategies among dental students in Saudi Arabia. Saudi Dent J 2013;25(3):97-105. DOI: 10.1016/j.sdentj.2013.05.002.

15. Pau A, Rowland ML, Naidoo S, et al. Emotional intelligence and perceived stress in dental undergraduates: a multinational survey. J Dent Educ 2007;71(2):197-204. DOI: 10.1002/j.00220337.2007.71.2.tb04266.x.

16. Fernández-Berrocal P, Cabello R, Castillo R, et al. Gender differences in emotional intelligence: the mediating effect of age. Behavioral Psychology 2012;20(1):77-89.

17. Saddki N, Sukerman N, Mohamad D. Association between emotional intelligence and perceived stress in undergraduate dental students.
Malays J Med Sci 2017;24(1):59-68. DOI: 10.21315/mjms2017. 24.1.7.

18. Rosli Tl, Abdul Rahman R, Abdul Rahman SR, et al. A survey of perceived stress among undergraduate dental students in university Kebangsaan Malaysia. Singapore Dent J 2005;27:17-22.

19. Peruzzo DC, Benatti BB, Ambrosano GMB, et al. A systematic review of stress and psychological factors as possible risk factors for periodontal disease. J Periodontol 2007;78(8):1491-1504. DOI: 10.1902/jop.2007.060371.

20. Goyal S, Gupta G, Thomas B, et al. Stress and periodontal disease: the link and logic!!. Ind Psychiatry J 2013;22(1):4-11. DOI: 10.4103/09726748.123585.

21. Shiralkar MT, Harris TB, Eddins-Folensbee FF, et al. A systematic review of stress-management programs for medical students. Acad Psychiatry 2013;37(3):158-164. DOI: 10.1176/appi.ap.12010003.

22. Nicole MM, Balogun SK, Oratile KN. Managing stress: the influence of gender, age and emotion regulation on coping among university students in Botswana. Int J Adolesc Youth 2014;19(2):153-173. DOI: 10.1080/02673843.2014.908784. 